\title{
3 Research Square \\ What Drives Energy Efficiency in Africa? Insights from 12 Selected Countries Using Incremental Decomposition Analysis
}

David Alemzero ( $\sim$ awelingazure@gmail.com )

Jiangsu University

\section{Sun Huaping}

Jiangsu University

\section{Research Article}

Keywords: Energy efficiency, total primary energy supply, decomposition analysis, Sub-Saharan Africa

Posted Date: September 9th, 2021

DOI: https://doi.org/10.21203/rs.3.rs-887117/v1

License: (c) (i) This work is licensed under a Creative Commons Attribution 4.0 International License.

Read Full License 


\title{
What Drives Energy Efficiency in Africa? Insights from 12 Selected Countries Using Incremental Decomposition Analysis
}

\author{
David Ajene Alemzero ${ }^{1 *}$, Sun Huaping ${ }^{1}$, \\ ${ }^{1}$ School of Economics and Finance Jiangsu University Zhenjiang, Jiangsu, 212013, China
}

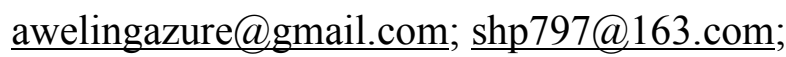

\begin{abstract}
This paper examines why Africa, and Sub-Saharan Africa (SSA) in particular, has some of the worse energy efficiency indicators in the world. It examines the relationship between total primary energy supply (TPES), final energy consumption, and transmission and distribution (T\&D) losses on the continent. We apply the Sun-Shaley incremental decomposition method of logarithmic mean divisia index (LMDI to twelve (12) African countries using data from 2000 to 2016 to decompose TPES into the effects of changes in final energy consumption (FEC), population change (POP), carbon dioxide (CO2) emissions, and economic activity measured by gross domestic product (GDP), and their impact on energy efficiency. The method provides a precise decomposition analysis and incremental results that can be added to study the long-run impacts without any information missing in between. The findings show that the study countries have worsening energy efficiency indicators with energy intensity (EI) as high as 55\%, coupled with an inefficient transformation of primary energy supply to final consumption, culminating in significant systems losses. It was further discovered that countries that have more significant proportions of renewables sources in their energy mix have lower transmission and distribution losses. This study serves as a guide to the policy discourse regarding the energy efficiency situation in Africa.
\end{abstract}

Keywords: Energy efficiency; total primary energy supply; decomposition analysis; Sub-Saharan Africa

\section{Introduction}

Energy availability and its use are indispensable components of the modern economy. However, energy resources must be managed well to make them continuously available to users, hence the need to improve energy efficiency and reduce energy intensity. Energy efficiency, in this context, refers to using less energy to undertake the same task, therefore eliminating energy waste - that is doing more with less (Islam and Hasanuzzaman, 2020). Energy intensity is the measure of the energy efficiency of a nation's economy, calculated as a unit of energy used per unit of GDP. It is an indication of how much energy is used to produce one unit of economic output.

Since the 1970s, various countries across the world encompassing developed and developing countries alike have adopted energy efficiency measures and initiatives as part of their energy and climate policies - that is, primarily to reduce CO2 emissions and improve energy security (Vehmas 
et al., 2018; Chang and Huang, 2020). In more recent times, improving energy efficiency and reducing intensity has become one of the important milestones under climate policy targets such as The Paris Agreement which seeks to limit global warming to under a $2{ }^{\circ} \mathrm{C}$ increase. For example, International Energy Agency (IEA) estimates show that a combination of the right energy efficiency policies has the potential to deliver more than $40 \%$ of emissions reductions needed to reach the goals of the Paris Agreement (IEA, 2018).

Since 2010, several African countries have been increasing power generation and expanding access to modern energy services to reduce poverty and inequality. Nevertheless, only $48 \%$ of the population had access to electricity in 2019, up from $33 \%$ in 2010 (IEA, 2020). In contrast, $87 \%$ of the population of developing economies had access to electricity in 2019 as compared to $74 \%$ in 2010 . This means that around 580 million people or about $50 \%$ of the population, mostly in Sub-Saharan Africa (SSA), did not have access to electricity (IEA, 2020; SEforALL, 2020). A challenge that remains to provide modern energy services to the remaining underserved population is how to do it in climate-smart ways. This is where energy efficiency could create important win-win opportunities.

Nevertheless, energy efficiency in Africa remains among the lowest in the world. Africa has the lowest per capita energy consumption in the world despite accounting for $17 \%$ of the global population (Atlas Africa, 2017; IEA, 2019). In general, Africa accounts for 3.3\% of global primary energy consumption, $6 \%$ of the world's energy demand, and less than $3 \%$ of global electricity demand (RES4A,2020). Also, electricity consumption on the continent is skewed as the northern and southern parts of Africa account for 71\% of Africa's 708 terawatt-hours (TWh) total consumption as of 2019 (IEA (2019). SSA, excluding South Africa, accounts for only $29 \%$ of total electricity consumption (RES4A,2020; IEA, 2019). Thus, amid this scarcity, it is prudent that Africa manages and expands its current electricity supply to ensure availability to all.

On the other hand, SSA remains one of the world's most energy-intensive regions (IRENA 2020; IEA 2020). That means SSA uses more energy to produce a unit of GDP than other areas in the world. This is compounded by technical and nontechnical factors such as high transmission and distributions (T\&D) losses, low-cost recovery, illegal connections, and several hidden costs in the form of tariff under-recovery and the poor financial ratings of the power utilities, making them unable to access debt financing (Trimble, 2016). For example, T\&D losses are as high as over 50\% in certain countries and putting most power utilities in a precarious financial situation. The narrative of the T\&D losses above explains why in some instances, over $50 \%$ of electricity produced remains unaccounted for in most SSA countries (Trimble, 2016).

While diversification of the energy matrix in Africa is ongoing, it remains at a slow pace. Renewables are forecasted to increase from $1 \%$ currently to $16 \%$ in 2040, and electricity demand nearly tripling by 2040 (BP, Africa, 2019). Furthermore, crude oil will still be the dominant fuel, forming $34 \%$ in fuel consumption by 2040 , a reduction from $44 \%$ today, with renewables overtaking coal to become the second-largest source for power generation in 2040. Africa's energy intensity is forecasted to fall by $12 \%$ by 2040 (BP Africa, 2019). The share of electricity in final energy consumption will increase to $23 \%$ by 2030 (McKinsey \& Company, 2019).

Given this background, this paper seeks to examine why Africa, and SSA in particular, has some of the worse energy efficiency indicators in the world. It also examines the relationship between total primary energy supply (TPES) on final energy consumption (FEC), and transmission and distribution (T\&D) losses on the continent. To do this, the study will decompose TPES into the effects of change in FEC, change in population (POP), carbon dioxide (CO2) emissions, and economic activity measured by gross domestic product (GDP). We use the Sun-Shaley incremental decomposition method of logarithmic mean divisia index (LMDI) to find answers to these nagging questions on the continent. The Sun-Shaley incremental decomposition method of LMDI is applied to twelve (12) 
countries using data from 2000 to 2016 to decompose and study changes in TPES, FEC, POP, CO2, GDP, and their impact on energy efficiency. In effect, the paper analyses these macroeconomic variables and their impact on energy efficiency performance of some selected African countries the efficiency of the total primary energy supply (TPES) transformation process.

This work adds to the literature in the following ways. Firstly, this work provides further insights into the trajectory of energy efficiency trends on the continent and makes recommendations on how to improve energy efficiency through policy design and formulation. Secondly, this work is unique in that, to the best of our knowledge, it is the only work that uses the Sun-Shaley of the LMDI family approach to analyze energy efficiency in Africa, looking at TPES. Even though studies have been done on Africa at the aggregate level - such as Pappi et al. (2019) - and on the individual country level — as done by Inglesi-Lotz and Blignaut (2011) and Olanrewaju (2019), the Sun-Shapley approach has not been applied in Africa.

The rest of the paper is organized as follows: Section Two reviews the relevant literature. This is followed by Section Three, which describes the applied experimental design, including methods. Section Four presents the results. Section Five summarizes the paper by providing conclusions about the main findings, implications for policymakers, and further research.

\section{Literature Review}

\subsection{State of Global Energy Efficiency}

Energy efficiency is one of the cornerstone policies needed for the world to move to a sustainable consumption pattern and ensure energy security. energy efficiency has manifold benefits such as economic, social, and environmental when its implementation is achieved. energy efficiency is a general term that has been defined by many authors. Patterson (1996) defined energy efficiency as using less energy to produce the same quantity of useful output of a good or service. In other words, it is the ratio of user input of a process to a valuable outcome of a process. The definition by Patterson highlighted the importance of using less energy to produce a large quantity of output. It does not mean using less energy to have less output. Furthermore, according to the United States Energy Information Administration (EIA), energy efficiency has been defined as using a technology that uses less energy to perform the same function. For instance, using a comparative light-emitting diode (LED) bulk or a compact fluorescent bulb versus an incandescent light bulb to produce the same amount of light (EIA,2019). The EIA contrasts this with energy conservation, like any behavior that leads to less energy use. When no one is in the room, putting off the light is a behavioral act to conserve energy (EIA, 2019).

Globally, energy efficiency has seen significant improvement. According to the IEA, primary energy intensity grew in 2018; less than $1.2 \%$ of energy is needed to produce each GDP unit, lower than required to make the same quantity in 2017. Besides this, the IEA Sustainable recovery plan projects $40 \%$ of the one trillion dollars budget for annual expenditure on energy efficiency distributed to the economy's various sectors. This will result in efficiency improvement for 20 million households yearly. Also, 350 million modern and efficient appliances are purchased and improved to industrial processes (IEA, 2020). This is also a significant reduction in energy costs due to adopted energy efficiency measures (IEA, 2020). Furthermore, Sustainable Development Goal (SDG) 7.3 seeks to double the energy efficiency improvement rate by 2030 based 1990-2010 trend, which was about $1.3 \%$. To achieve SDG7.3, the world needs a 3\% annual reduction from now to 2030, which is daunting (IRENA, 2020). 
The IEA (2019) contends that the rapid improvement in energy efficiency would be the catalyst to transition the world towards a sustainable development future. This would be underpinned by a drastic transformation of the energy sector at a scale to catapult many developing countries including Africa to a sustainable future. It encompasses a paradigm shift in the ways energy is consumed and supplied, coupled with removing barriers to the deployment of energy efficiency such as financial, information asymmetry and regulatory costs (IEA, 2019).

Since 2010, several countries and regions have increased the adoption of policy and regulatory frameworks to scale up energy efficiency adoption (World Bank, 2020). This is shown by the RISE - Regulatory Indicators for Sustainable Energy - sub-indicator on energy efficiency. As of 2019, about $70 \%$ of RISE participating countries had adopted legislation planning for energy efficiency, although South Asia and Sub-Saharan Africa had the lowest scores (Figure 1). The data indicates that countries such as Ghana, Kenya, Egypt, Cameroun, Algeria, Morocco, Cote d'Ivoire Tunisia, and South Africa are faring well in the energy efficiency score (Figure 2). Africa's improvement in its energy efficiency score is stated in the IEA Sustainable development scenarios, where global energy intensity improves substantially, averaging $3.6 \%$ a year, with Africa improving significantly towards 2040 (IEA, 2019).

\section{Figure 1 Regulatory Indicators for Sustainable Energy (RISE) Efficiency Scores}

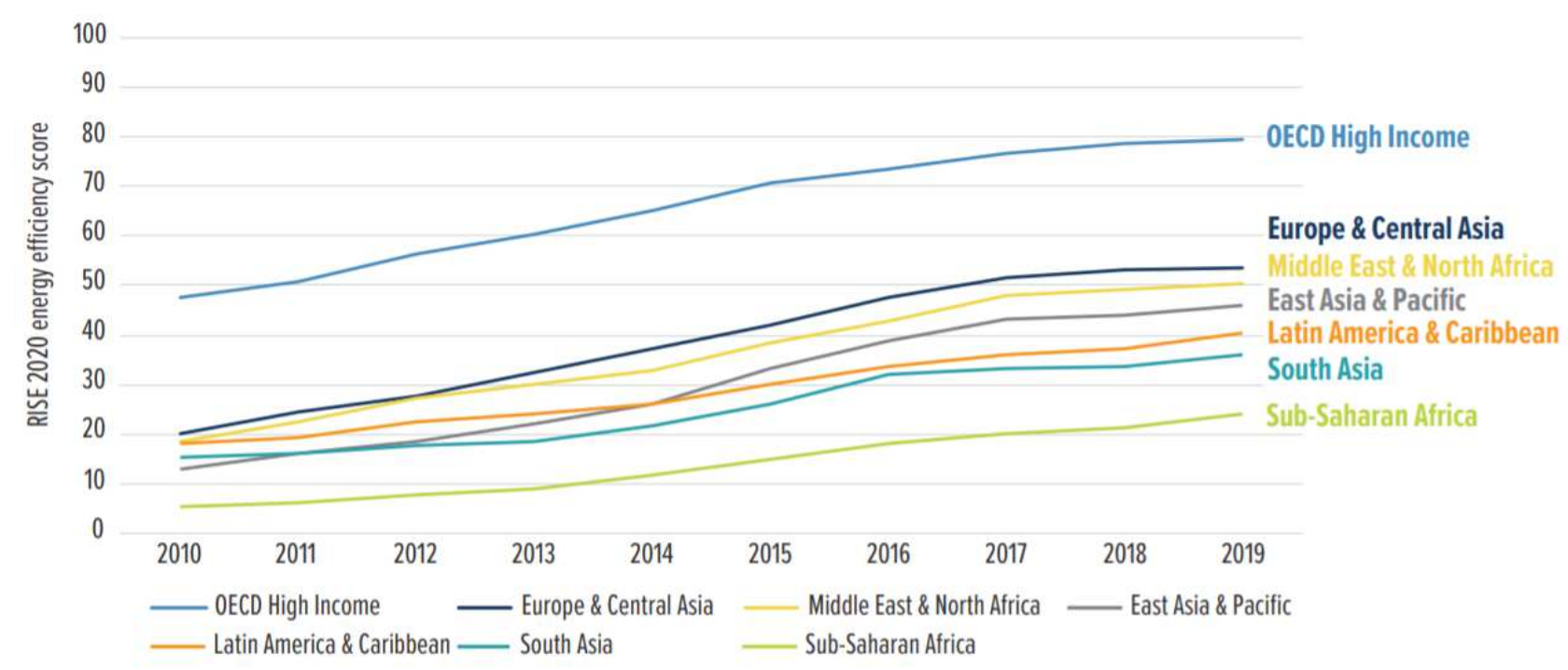

Source: World Bank, RISE 2020

Figure 2 RISE scores for African countries between 2010 and 2017 


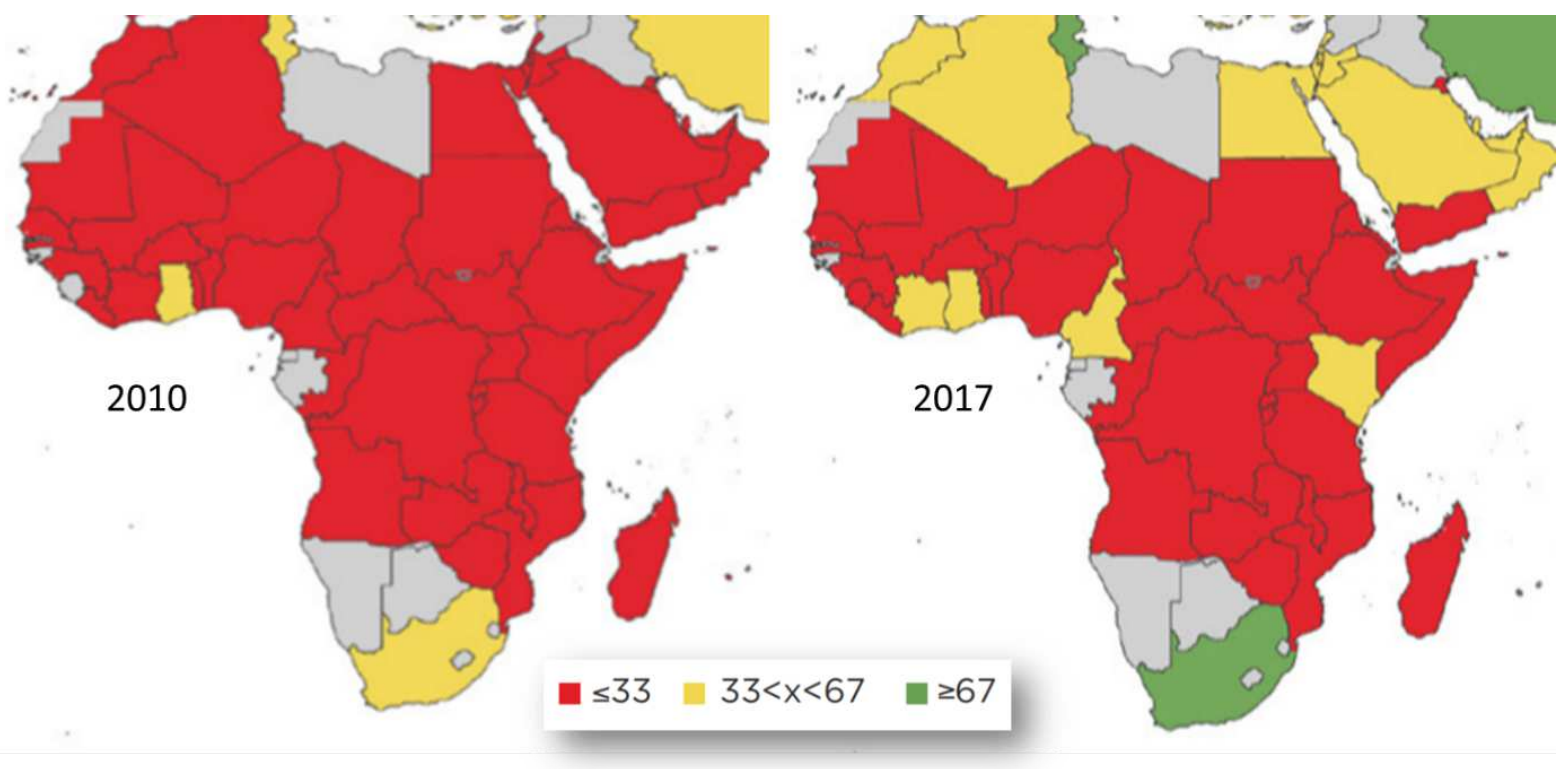

Source: World Bank RISE 2018

\subsection{Energy Efficiency Estimation Methods and Relevant Empirical Works}

As Figure 3 shows, energy efficiency decomposition can be done multiplicatively or additively, where the difference in change can be segregated using either traditional single-factor productivity analysis or multifactor productivity analysis. Pillai (2019) has identified four indicators to track changes in energy efficiency. Pillai (2019) has identified four indicators to track changes in energy efficiency. The first is a thermodynamic indicator, which sums up the energy of useful output of a process to input. The drawback of this process is that it is not ideal for measuring energy quality and macro-level activity(Pillai, 2019). Second is the physical dynamic, which explains energy efficiency as the ratio between the output of material and the variation in energy input in a circle. The third is economic -thermodynamic- that is a double-headed approach that measures energy in thermodynamics units and output in market prices. Finally, financial measures production in monetary value and measures energy in thermodynamic unit

\section{Why LMDI is essential}

There are different methods of the Logarithmic Division Index (LMDI). The reasons for choosing any decomposition approach are the theoretical bases, ease of use, adaptability, and ease of interpretation. This method is readily applicable to specific energy subsectors to estimate energy efficiency savings. Thus, it makes it plausible to estimate the TPES on energy efficiency in the selected countries in Africa. More so, it gives easy formulation and interpretation without having to explain the residual term.

The approach is very novel in its process for the African context, to evaluate the trends of energy efficiency on the continent for the study period. This study makes use of the Sun-Shapley additive method, which has been applied in research to study cost allocation, which was pioneered by Albrecht et al. (Ang, 2004) to energy decomposition study. Ang (2004) highlighted Sun and proposed a similar approach to the Shapley decomposition. This approach has become known as the fine-tune Laspeyres index approach that entails decomposing the interaction terms in the traditional Laspeyres index to the main effects. As a result, the Sun-Shaley decomposition approach has been coined to 
give a complete decomposition. When the segregation method involves two factors, the Sun-Shaley approach is referred to as the Marshall-Edgeworth Method.

Figure 3 Energy efficiency estimation methods

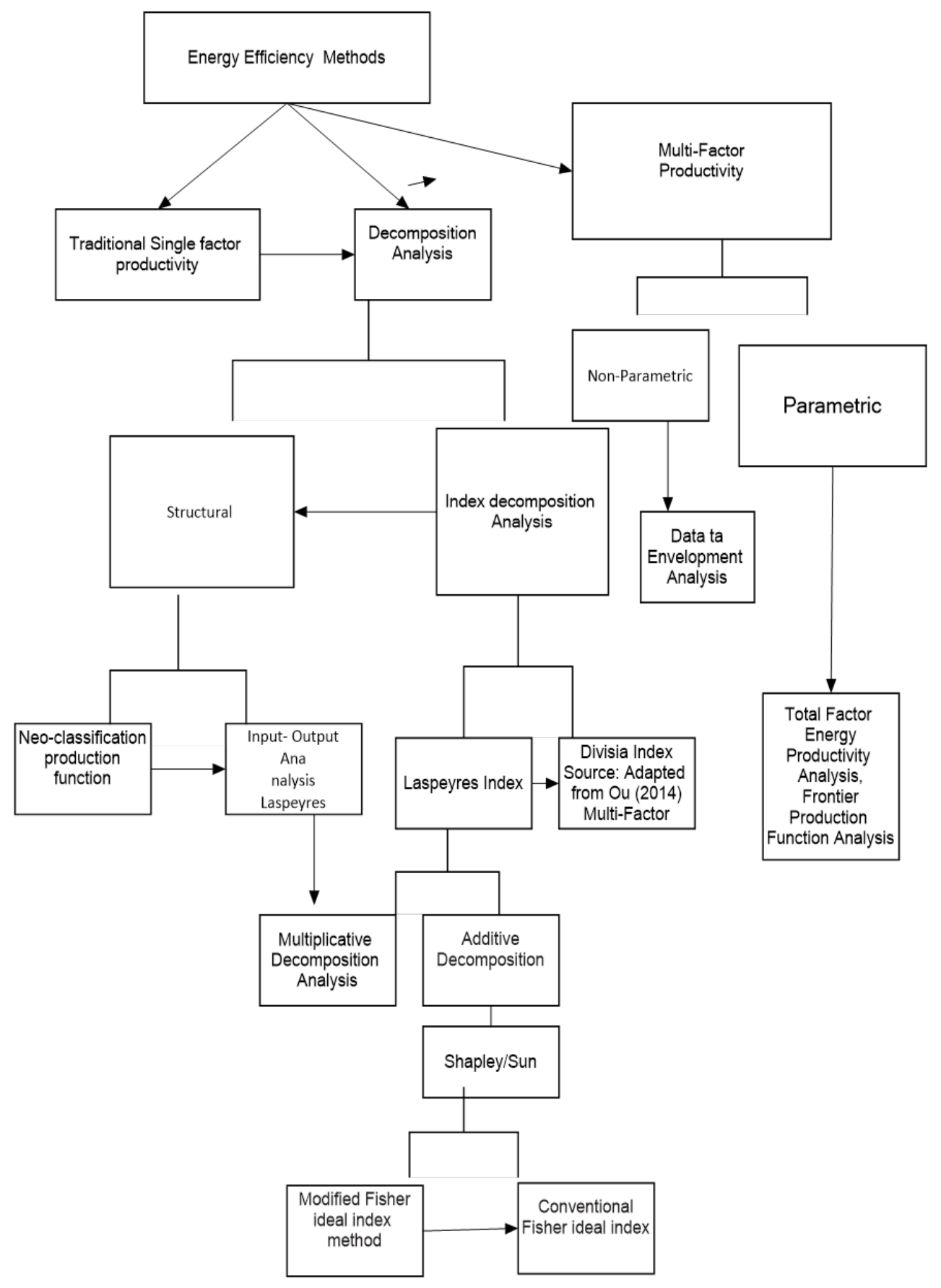

Chang and Huangn (2020) using multiplicative, additive LMDI for 18 Asia-Pacific Economic Cooperation (APEC) countries between 1971-2015 found that population increase coupled with economic growth brought about increased carbon dioxide $(\mathrm{CO} 2)$ emissions among these countries and improvement in their energy efficiency. A further study in the Chongqing area applied the LMDI, looked at the industrial energy use and using the industrial carbon emission approach (ICE), 
discovered that these factors influence the ICE, energy intensity, energy mix, industrial output, and structure. They further said industrial output is the main driver for ICE.

Olanrewaju (2019) using the LMDI between 1994-2016 to decompose and analyze South Africa's sub-industrial sectors, found three factors to determine energy consumption. These were structural, activity, and intensity. The energy activity effect accounted for a bulk of the energy consumed in the industrial sectors, while the intensity effect reduces energy consumption.

Cansino et al., (2015) studied the dynamics of energy consumption in Spain using the LMDI decomposition approach from 2003-2012 revealed that reduction of final energy consumption of 1\% was achieved due to an $11 \%$ diminishing structural effect, while growth in intensity effect and activity effect was $3.5 \%$ and $7 \%$ respectively.

Another study by Inglesi-Lotz (2018) that sought to test the hypothesis of "'rebound effect'" or "'Take back effect" in South Africa from 1990-2014, by studying the drivers of changes in CO2 emission levels and drawing comparisons to BRICS countries, discovered by the decomposition approach that $\mathrm{CO} 2$ intensity and energy intensity had no impact on the changes on $\mathrm{CO} 2$ emissions levels on all the nations. In other words, as energy intensity decreases, CO2 increases. And for South Africa per se, its energy intensity was a negative indicator of its emissions levels for the period studied.

Similarly, a study by Kim (2017) on the Korea Manufacturing sector from 1991-2011, using the LMDI, concluded that the activity effect was a driving force behind an increase in energy consumption. And that the structure and intensity effect were the reasons for the reduction in consumption in the Korean Manufacturing sector. There was an inverse relationship with the structural impact and intensity effects, as structure effect increases; intensity reduces, with products having varied implications on the various sub-sectors.

Furthermore, a study by Moutinho et al., (2018) on the impact of CO2 emissions on top 23 countries on renewable energies globally, from 1985-2011, using LMDI found that electricity financial power effects (EF) have contributed to an increased in the emissions of $\mathrm{CO} 2$ While renewable resources productivity(RP) effect has led to falling in $\mathrm{CO} 2$ emissions for all countries.

These results corroborate majors findings that countries with more significant proportions of renewable resources in the primary Consumption have lesser $\mathrm{CO} 2$ emission levels(Pascumal etal 2019)(Trimble, 2016), as shown in table 3.

\section{Methodology}

\subsection{Decomposition analysis}

Decomposition analysis has become the most preferred method for analyzing energy efficiency research. Two forms of decomposition analysis exist in literature; there is index composition analysis, which uses aggregate time-series data (IDA), and structural decomposition analysis, which uses disaggregated data. The index decomposition analysis had become more popular since the 1980s when papers were published using that approach.

The 1973 oil crisis, coupled with the rising climate concerns, popularized energy efficiency as studies using this approach gained currency by researchers due to the need by nations to look for ways to maximize energy use in the face of rising oil prices. Thus, leading to the development of the index methodology in the United States in the 1970s and the UK (Pillai, 2019). This ignited particular research interest in the decomposition approach. The most popular was the Laspeyres index, and in the 1990s beyond, the Divisia index became famous, the logarithmic mean Divisia index (LMDI) to be precise. 
Based on the reasons mentioned above, data from the African Energy Commission (AFREC) and the world Development were derived from undertaking the decomposition analysis from 2000-2016. The Sun/Shapley incremental approach is one of the most practicable means of analyzing decomposition studies.

A significant amount of studies have been done on IDA concerning energy intensity changes; see (Pillai, 2019), (Ang and Zhang (2000) for a study on decomposition analysis. There are two critical types of Divisia index decomposition methods, Arithmetic mean (AMDI) and Logarithmic Mean Divisia Index (LMDI). Many studies have been done on IDA on Energy-related aggregate consumption, like primary energy consumption, $\mathrm{CO} 2$ emissions, and energy intensity.

The decomposition analysis gives the following changes

$$
C 02=\left(\frac{C O 2}{T P E S}\right) \times\left(\frac{T P E S}{F E C}\right) \times\left(\frac{F E C}{G D P}\right) \times\left(\frac{G D P}{P O P}\right) \times P O P
$$

Is the KAYA identity that is decomposed to analyze the data

CO2 $=$ Carbon dioxide

TPES=Total primary energy supply

$F E C=$ Final energy consumption

$G D P=$ Gross domestic product

$P O P=$ Population

$$
T P E S=\frac{T P E S}{F E C} X \frac{F E C}{G D P} X \frac{G D P}{P O P} X P O P
$$

Equation (2) is the decomposition of TPES by taking the ratios of each variable.

$$
\frac{T P E S}{F E C}=\left(F E C_{t-1}+\lambda 1 F E C_{t t-1}\right) \times \Delta\left(\frac{T P E S}{F E C}\right)_{t t-1}
$$

Equation (3) is the ratio of TPES/FEC, where $F E C_{t-1}$ is the final energy consumption of the previous year. In all the equations, the parameters $\lambda 1, \lambda 2$, and $\lambda 3$ indicate how to arrive at the two variables in each equation of the decomposition analysis.

According to (Vehmas et al., 2018), following the " principles jointly created and equally distributed of the Sun -Shapley method, $\lambda 1=, \lambda 2=\lambda 3=0.5$ in their analysis, the same value for $\lambda$ is applied in 
this research. Subscript $t-1$ refers to a moving base year (And the previous year is $t$ ), and subscript $t t-1$ to a difference $\Delta$ the current year $t$ and the previous year $t-1$

$$
\left.F E C=\left\lfloor\left(\frac{T P E S}{F E C}\right)_{t-1}+(1+\lambda 1) \Delta\left(\frac{T P E S}{F E C}\right)_{t t-1}\right\rfloor \times F E C_{t t-1}\right)
$$

Equation (4) is the decomposition for final energy consumption, taken as a total primary energy supply ratio over final energy consumption. The parameter $\lambda 1=0.5$

Subscript $t-1$ refers to a moving base year (And the previous year is $t$ ), and subscript $t t-1$ to a difference $\Delta$ change the current year $t$ and the last year $t-1$

$$
\begin{gathered}
\frac{F E C}{G D P}=\left\lfloor\left(\frac{T P E S}{F E C}\right)_{t-1}+(1+\lambda 1) \Delta\left(\frac{T P E S}{F E C}\right)_{t t-1}\right\rfloor X\left(G D P_{t-1}+\lambda 2 G D P_{t t-1}\right) \\
\times \Delta\left(\frac{F E C}{G D P}\right)_{t t-1}
\end{gathered}
$$

The equation represents the decomposition for final energy consumption and gross domestic product. Subscript $t-1$ refers to a moving base year (And the previous year is $t$ ), and subscript $t t-1$ to a difference $\Delta$ /change the current year $t$ and the last year $t-1$

$$
\begin{aligned}
G D P=\left\lfloor\left(\frac{T P E S}{F E C}\right)_{t-1}+(1+\lambda 1) \Delta\left(\frac{T P E S}{F E C}\right)_{t t-1}\right\rfloor \\
\times\left[\left(\frac{F E C}{G D P}\right)_{t-1}+(1+\lambda 2) \Delta\left(\frac{F E C}{G D P}\right)_{t t-1}\right] \times G D P_{t t-1}
\end{aligned}
$$

Equation (6) is the decomposition analysis for GDP. Subscript $t-1$ refers to a moving base year (And the previous year is $t$ ), and subscript $t t-1$ to a difference $\Delta /$ change the current year $t$ and the last year $t-1 .\left(\frac{T P E S}{F E C}\right)$ Is the ratio of total primary energy supply over final energy consumption $\left(\frac{F E C}{G D P}\right)$ Is Final energy consumption over gross domestic product. The parameter $\lambda 2=0.5$

$$
\begin{aligned}
& \frac{G D P}{P O P}=\left\lceil\left(\frac{T P E S}{F E C}\right)_{t-1}(1+\lambda 1) \Delta\left(\frac{T P E S}{F E C}\right)_{t t-1}\right\rceil\left\lceil\left(\frac{F E C}{G D P}\right)_{t-1}+(1+\right. \\
& \left.\lambda 2) \Delta\left(\frac{F E C}{G D P}\right)_{t t-1}\right\rceil \times\left(P O P_{t-1}+\lambda 3 \Delta P O P_{t t-1}\right) \times \Delta(G D P / P O P)_{-}(t t-1)
\end{aligned}
$$

Equation (7) is the decomposition analysis for GDP per capita. Subscript $t-1$ refers to a moving base year (And the previous year is $t$ ), and subscript $t t-1$ to a difference $\Delta /$ change the current year $t$ and the last year $t-1$. The parameter $\lambda 3=0.5$

$$
\begin{aligned}
& P O P=\left\lceil(T P E S / F E C)_{-}(t-1)(1+\lambda 1) \Delta(T P E S / F E C)_{-}(t t-1)\right\rceil \times\lceil(F E C / \\
& \left.G D P)_{-}(t-1)\right\rceil+(1+\lambda 2) \Delta(F E C / G D P)_{-}(t t-1) \times[(G D P / P O P)]_{-}(t-1)+ \\
& \left.(1+\lambda 3) \Delta\left(\frac{G D P}{P O P}\right)_{t t-1}\right] \times \Delta P O P_{t t-1}
\end{aligned}
$$


Equation (8) is the decomposition analysis for the population. Subscript $t-1$ refers to a moving base year (And the previous year is $t$ ), and subscript $t t-1$ to a difference $\Delta / \operatorname{change}$ the current year $t$ and the last year $t-1$. The parameter $\lambda 3=0.5(F E C / G D P)$ is final energy consumption over gross domestic product. $\left(\frac{G D P}{P O P}\right)$ Is the gross domestic product.

\subsection{Data}

The study makes use of data from 2000-2016 from the African Energy Commission(AFRC) and additional data from the WDI on the EE indicators of these countries applying the LMDI Sun/Shapley approach. The data was obtained regarding their total primary energy supply (TPES), their population size (POP), carbon dioxide emission levels (CO2), their gross domestic production (GDP), and their final energy consumption (FEC).

Table 1 Indicators of selected countries.

\begin{tabular}{|c|c|c|c|c|c|c|c|}
\hline & $\begin{array}{l}\mathrm{CO} 2 \\
\text { Emissions- } \\
\mathrm{MtCO} 2\end{array}$ & TPES & $\begin{array}{l}\text { Share of } \\
\text { fossil fuels } \%\end{array}$ & $\begin{array}{l}\text { GDP per } \\
\text { capita } \\
\text { (current } \\
\text { US\$) }\end{array}$ & Population (Millions) & $\begin{array}{l}\mathrm{CO} 2 \text { per } \\
\text { Capita }\end{array}$ & $\begin{array}{l}\text { GDP per } \\
\text { capita, } \\
\text { PPP } \\
\text { (constant } \\
2017 \\
\text { internatio } \\
\text { nal \$) }\end{array}$ \\
\hline Algeria & 145,400 & 60,390 & $54 \%$ & 4,115 & 40,551 & 3.74 & 4,115 \\
\hline Angola & 34,763 & 13,611 & $34 \%$ & 3,432 & 28,842 & 1.29 & 6,924 \\
\hline Cape Verde & 491 & 3,174 & $18 \%$ & 3,635 & 531 & 3.37 & 6,900 \\
\hline DR Congo & 4,672 & 35,551 & $2 \%$ & 562 & 78,789 & 0.95 & 1,085 \\
\hline Egypt & 201,894 & 89,072 & $42 \%$ & 2,549 & 94,447 & 2.23 & 11,366 \\
\hline Ethiopia & 11,599 & 48,567 & $7 \%$ & 772 & 103,604 & 1.75 & 2,103 \\
\hline Morocco & 59,864 & 17,932 & $47 \%$ & 3,222 & 35,126 & 8.98 & 7,641 \\
\hline South Africa & 489,772 & 134,690 & $48 \%$ & 6,374 & 56,208 & 0.55 & 12,631 \\
\hline Nigeria & 96,281 & 134,690 & $14 \%$ & 2,028 & 185,960 & 0.55 & 14,080 \\
\hline Libya & 56,996 & 24,753 & $50 \%$ & 7,242 & 6,492 & 0.53 & 5,194 \\
\hline Ghana & 14,466 & 9,486 & $34 \%$ & 2,202 & 28,482 & & 4,193 \\
\hline Kenya & 14,287 & 20,850 & $20 \%$ & 1,711 & 49,052 & 0.31 & 4,193 \\
\hline
\end{tabular}

Table 1. Algeria has the highest Carbon dioxide emissions in a million tonnes and the highest share of fossil fuel in the TPES of 54\%. It is equally reflected in the GDP per capita of the countries. The more income people can spend more on energy consumption. (Sun et al., 2020). The result revealed that North Africa countries have the highest carbon emissions, GDP per capita, and

enormous fossil fuels in their TPES. The result is significantly different for SSA; SSA countries tend to have lower carbon emissions, lower GDP per capita, and lower energy consumption levels. Further 
analysis shows that Countries like DRC, Ethiopia, Cape Verde, and Kenya have a smaller share of fossil fuels in their primary energy supply (TPES). Conspicuously, these countries generate more of their electricity from renewables like hydro, wind, geothermal, resulting in a smaller percentage of fossil fuel in the TPES.

Table 2 Data and Indicators of the of the study countries

\begin{tabular}{|c|c|c|c|c|c|c|c|c|c|c|c|}
\hline Country & TFC & $\begin{array}{l}\text { POP- } \\
\text { millions }\end{array}$ & GDP & $\mathrm{CO} 2$ & $\begin{array}{l}\mathrm{CO} 2 / \mathrm{P} \\
\mathrm{OP}\end{array}$ & $\begin{array}{l}\mathrm{CO} 2 / \mathrm{G} \\
\mathrm{DP}\end{array}$ & $\begin{array}{l}\text { TFC/P } \\
\text { OP }\end{array}$ & $\begin{array}{l}\text { TFC/G } \\
\text { DP }\end{array}$ & T\&D losses & $\begin{array}{l}\text { Share } \\
\text { of RES } \\
\text { in FEC }\end{array}$ & TPES \\
\hline Algeria & 37,118 & 39 & 11,480 & 114 & 3.7 & 3 & 947 & 3 & $135,000,000$ & 0 & 60,390 \\
\hline Angola & 9,334 & 21 & 6,924 & 18 & 1.3 & 2 & 435 & 1 & $10,958,500$ & 55 & 13,611 \\
\hline $\begin{array}{l}\text { Cape } \\
\text { Verde }\end{array}$ & 165 & 1 & 6,900 & 0 & 0.9 & 5 & 326 & 0 & $1,298,570$ & 25 & 3,174 \\
\hline $\begin{array}{l}\text { DR } \\
\text { Congo } \\
\end{array}$ & 18,981 & 68 & 1,085 & 3 & 0.1 & 0 & 281 & 17 & $11,141,018$ & 97 & 35,551 \\
\hline Egypt & 55,413 & 82 & 11,366 & 184 & 2.2 & 3 & 675 & 5 & $273,000,000$ & 6 & 89,072 \\
\hline Ethiopia & 40,172 & 94 & 2,103 & 9 & 0.1 & 0 & 427 & 19 & $16,258,610$ & 92 & 48,567 \\
\hline Morocco & 14,584 & 33 & 7,641 & 14 & 1.8 & 3 & 442 & 2 & $\begin{array}{l}5,240,000,00 \\
0\end{array}$ & 11 & 17,932 \\
\hline $\begin{array}{l}\text { South } \\
\text { Africa }\end{array}$ & 65,061 & 53 & 12,631 & 420 & 9.0 & 3 & 1,224 & 5 & $377,000,000$ & 14 & 134,690 \\
\hline Nigeria & 1,224 & 174 & 5,156 & 61 & 0.5 & 1 & 7 & 0 & $91,275,000$ & 82 & 134,690 \\
\hline Libya & 19,000 & 6 & 14,080 & 43 & 9.0 & 3 & 3,065 & 1 & $156,000,000$ & 2 & 24,753 \\
\hline Ghana & 6,868 & 26 & 5,194 & 14 & 0.5 & 2 & 269 & 1 & $37,588,060$ & 42 & 9,486 \\
\hline Kenya & 15,788 & 44 & 4,193 & 12 & 0.3 & 1 & 360 & 4 & $23,318,000$ & 72 & 20,850 \\
\hline
\end{tabular}

Table 2 provides the country statistics; the more developed countries on the continent such as Algeria, South Africa, Morocco, Egypt tend to have the highest emission per capita, energy intensity, carbon intensity, per capita consumption, and total primary energy supply. The emissions ratios bring to the fore the fact these countries have not been able to decouple energy demand from economic growth and development. They equally exhibit high transmission and distribution losses. All these show that improvements in energy efficiency have been slower and almost nonexistent in most countries. On the other, the less developed countries, particularly those from Sub-Saharan Africa, except for South Africa, are lagging in efficiency programs and exhibit worse figures for energy efficiency indicators such as energy intensity, Per capita consumption; in contrast, they have a growing population. The Rise Africa report confirms this assertion SSA is far behind regarding energy efficiency programs(Rise Africa, 2018)

\section{Results and Discussion}


During the past 16 years, the study countries' total primary energy supply (TPES) increased by $106 \%$. This implies the study countries have increased their consumption of energy supply in more than a decade. This is in line with global TPES which will increase by 12, 100 Mtoe by 2010 and 16, 300 Mtoe by 2030(Mathew, 2007).

Besides, Africa's energy needs are met from different sources; the share of fossil fuel consumption doubled in the study period reaching 93\%, increasing from 222,069.4 kilograms to 430,281.6 kilograms. This is in tandem with a global fossil fuel increase of 70\% in 2019(IEA, 2019) ('Energy Efficiency, 2020). The rate at which energy is being consumed indicates the economic development of the economies. The increment explains the growing need for energy consumption to keep pace with economic development in the study countries.

Africa's population is increasing day by day. From 2000 to 2016, Africa's population more than doubled to more than 1 billion people. Due to the increasing population, energy demand will increase due to the demand for, industrialization, modern buildings, and energy services, creating more need for energy to meet these sophisticated lifestyles. This trend has been growing in Africa, resulting in primary energy supply increased by $106 \%$ during the study period.

The percentage of GDP per capita of Africa has increased by less than $50 \%$. This explains the economic prosperity of the countries. This indicator has a direct relationship with per capita energy consumption. This is because the better off a nation, the country's ability to spend on energy consumption. Higher-income levels translate to higher disposable, making citizens able to spend on cooling and heating appliances in the study countries. The rising middle class in Africa with better spending power shows people can afford comfortable lives. If these lifestyles are not energy efficient, they will increase the energy intensity of these economies, stalling progress towards energy efficiency.

Final energy consumption has increased by $96.3 \%$. Final energy consumption has not increased at the same rate as the total primary energy supply. Africa being at the brink of population explosion means, more energy will be demanded in the next two decades.

Africa's global CO2 continues to be insignificant and does not warrant concerns. This does not imply that Africa should not take steps to reduce its emissions levels since the changing impacts of climate change are global, not local. It has increased by $50 \%$. This is relatively high given that most of the continent's top emitter in the study is South Africa. However, the power sector emits so much $\mathrm{CO}_{2}$ as electricity consumption increases, creating a bidirectional relationship between $\mathrm{CO}_{2}$, and electricity generation, particularly on fossil fuels generation(Pascumal etal 2019)(Chakamera and Alagidede, 2018). Thus, the need to practice energy efficiency to ensure that the emissions levels are reduced. 


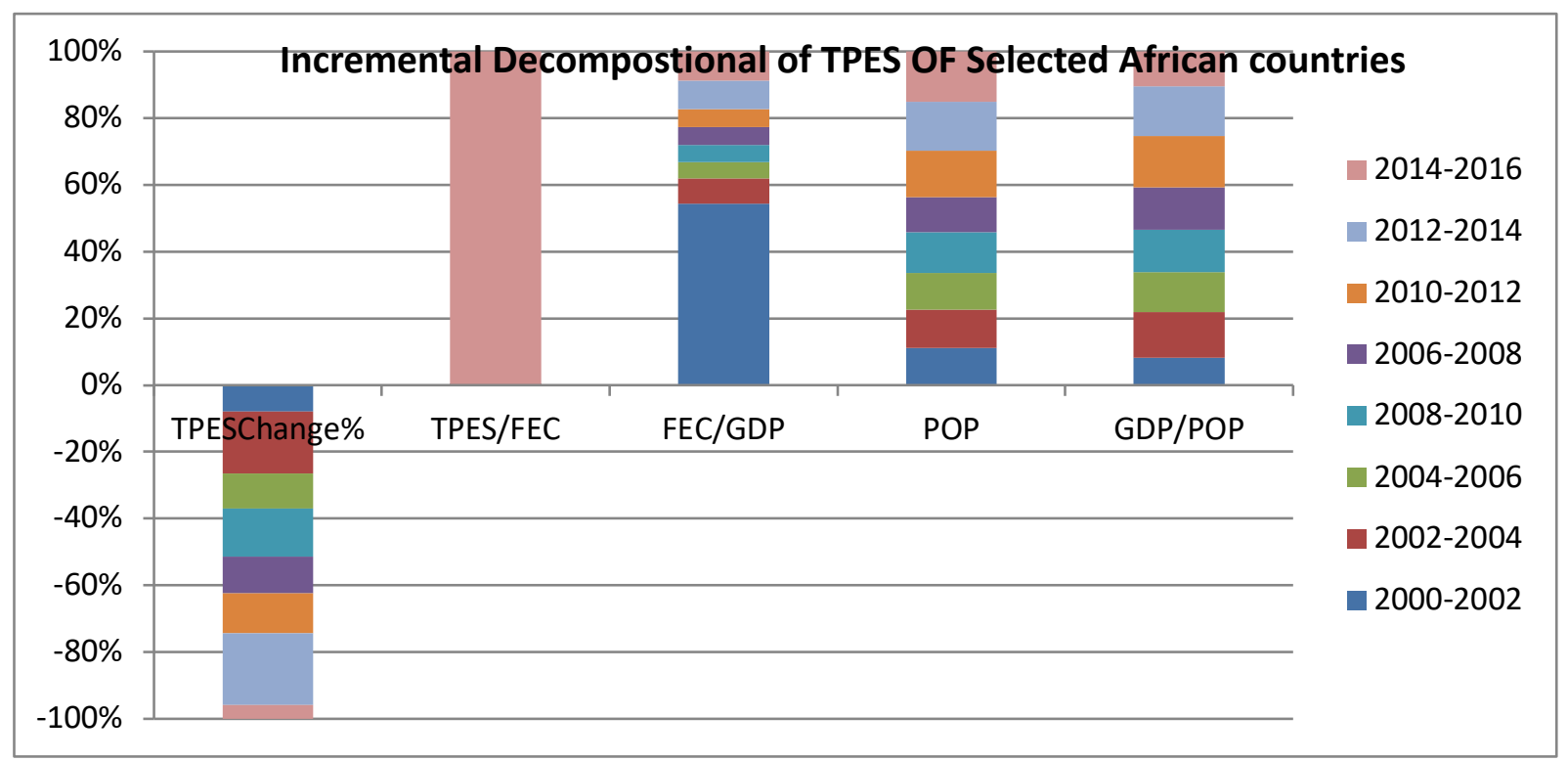

Figure 4. Incremental decomposition analysis of TPES selected African countries

\section{Source Author}

The percentage of TPES does not change considerably but decreases around 2004 and continues as the years go by. This explains the less diversified energy mix of the study countries. The increment is tilted towards fossil fuels instead of renewables. The percentage for TPES has been more than $100 \%$ for the study period. The analysis also found TPES/FEC to be decreasing among the study countries. The TPES/FEC explains a country's efficiency in transforming its primary energy sources for final consumption.

Most of the study countries have high T\&D Losses as high as $50 \%$ ( Trimble, 2016). Besides, if a country consumes more of its energy as electricity, it is likely to have T\&D losses because of the technical conversion processes that the electricity is produced. It must be stated that a country is doing well when its TPES/FEC and FEC/GDP are falling in value. On the other hand, the macroeconomic variables such as POP and GDP/POP are suitable for a country when the said country is experiencing increases in them. An increase in population gives more labor to the market, and a per capita income increases income levels.

Furthermore, the FEC/GDP ratio, which denotes the amount of energy used to produce a GDP unit, is relatively high in Africa. It is otherwise referred to as energy intensity. Africa is touted as an energy intensity continent. Africa's energy intensity has been lagging behind many other continents (RISE, 2021). South Africa is Africa's energy intensity country due to its reliance on coal for electricity consumption (Alemzero et al., 2020). The increased consumption of renewables in electricity will reduce the high $T \& D$ losses that are associated with the conversion of fossil fuels to electricity. Thereby improving the energy efficiency rates of these countries (IEA, IRENA 2020) 


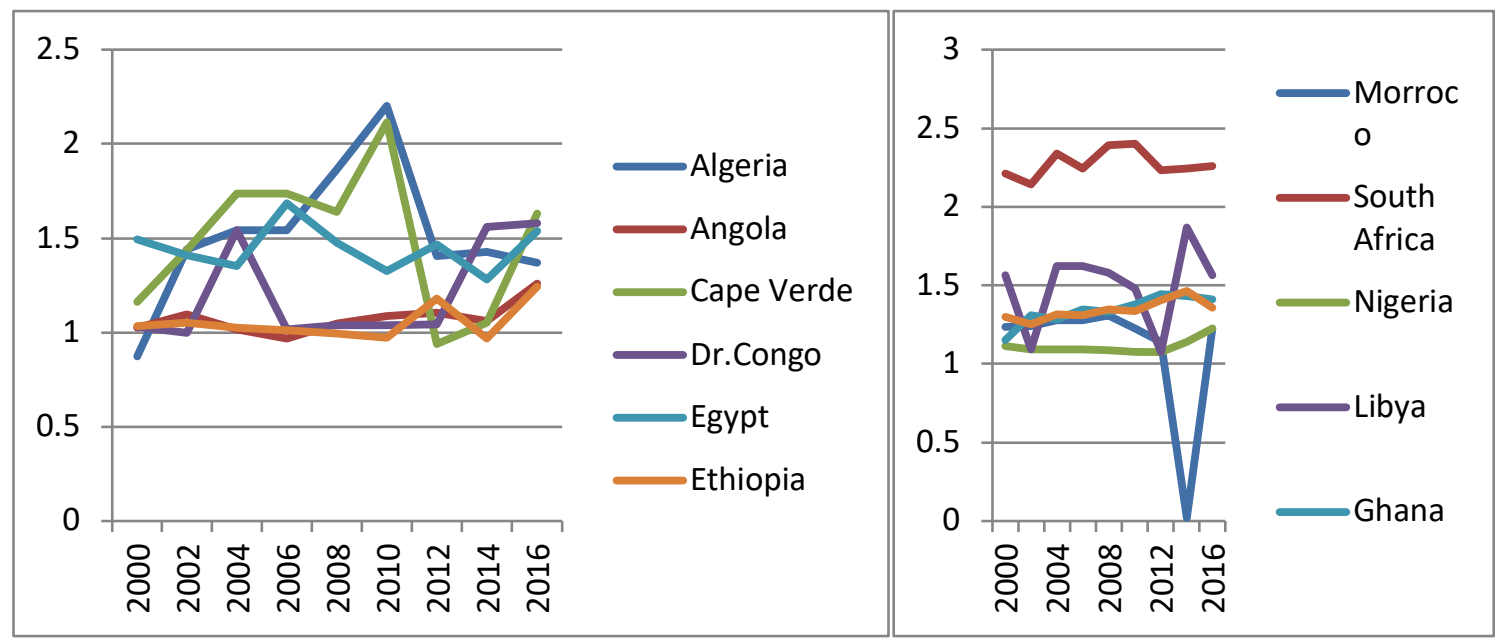

Figure 5 Trends of Energy TPES/FEC ratios of Angola, Cape Verde, DR.Congo, Egypt, Algeria, Kenya, South Africa, Nigeria, Ghana, Ethiopia, Morocco, and Libya. Between 2000-2016. Total energy supply is (Mtoe), Final energy consumption is (Mtoes). The smaller the value, the more energy-efficient a nation is.

It is apparent from the analysis that some of the study countries have made significant inroads regains regarding efficiency due to structural and reforms and activity effects adjustment. The efficiency of the transformation process has been steady for most countries except Egypt at the beginning of the study period. However, they all peaked in the 2006-2008 period, except Ethiopia, implying a worsened energy efficiency period. Similarly, there was an improvement from 2010-2012 for all the countries, and the trend seems to deteriorate from 2016. (Pascumal et al 2019) found the transformation effect to deteriorate but did not give an elaborate reason that account for that, nevertheless, this study found that the less integration of renewables has accounted for the deterioration of the transformation effect. Countries in this study that have more renewables in their generation mix have a better transformation effect.

South Africa is also an outlier from the analysis with the highest energy-inefficient sector (right figure). The structure of the economy is tilted toward fossil fuels, coal to be exact. However, there has been a recent move to diversify into renewables like wind and solar with the Integrated Resource Plan (IRP). Together with Morocco, Ghana is the north star in this group of countries with smaller TPES/FEC ratios, followed by Kenya and Nigeria. Their ratios are corroborated by the (RISE 2021) study, where they scored above $70 \%$ and $60 \%$, respectively.

Overall, the study countries' technical energy efficiency has not improved significantly due to the results arrived at, and the structural and activity effects are prevailing in the study countries.

Figure 5. TPES/FEC 


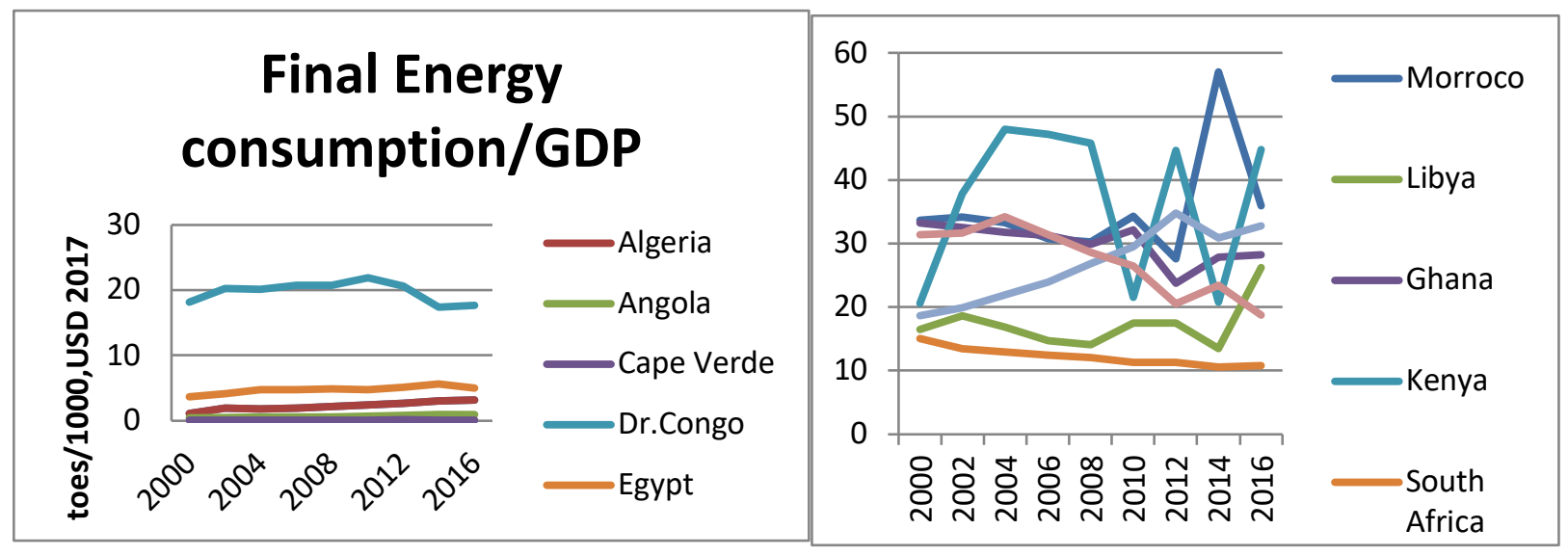

Figure 6 FEC/GDP

The energy Intensity Effect for Ghana began with the highest energy intensity (EI) ratio. However, they all increased from 2003-2005, implying these countries consume more energy relative to the GDP. One noticeable trend for this study group of countries on the left is that they are all on a steady growth path, suggesting that the activity effect is stable. It is no surprise because apart from DR Congo, the rest of the countries have a higher GDP per capita. More so, Egypt is the most energy intensity country in Africa(Alemzero et al., 2020). They all went into a trough from 2008-2014. 2008 financial crisis that hit the world reducing the activity effect of the economic on these countries. Trends of energy intensity for Algeria, Cape Verde, D.R. Congo, Egypt, Angola and South Africa, Nigeria, Egypt, Ethiopia, Morocco, Libya, and Ghana for the period 2000-2016.FEC/GDP is Final energy consumption divided by gross domestic product (GDP) is 2011 USD PPP.

The electricity supply share will determine the efficiency of the country's energy performance and the proportion of renewables in the electricity mix. The DR.has the most energy-intensive economy from the figure, as shown below (on the left-hand side). The rest of the countries are on a steady energy intensity pathway.

On the right-hand side, all the countries went into a trough in 2008 and peaked again in 2014. The 2008 financial crisis impacted the global economy; their energy intensity levels were reduced. A startling result was derived from South Africa with the most stable EI value. It is surprising because South Africa is the most energy-intensive economy on the continent. This result confirmed a study by (RISE 2021) where its overall EE score was above $70 \%$.

Figure 6Transmission and Distribution losses and Share of RES in FEC 


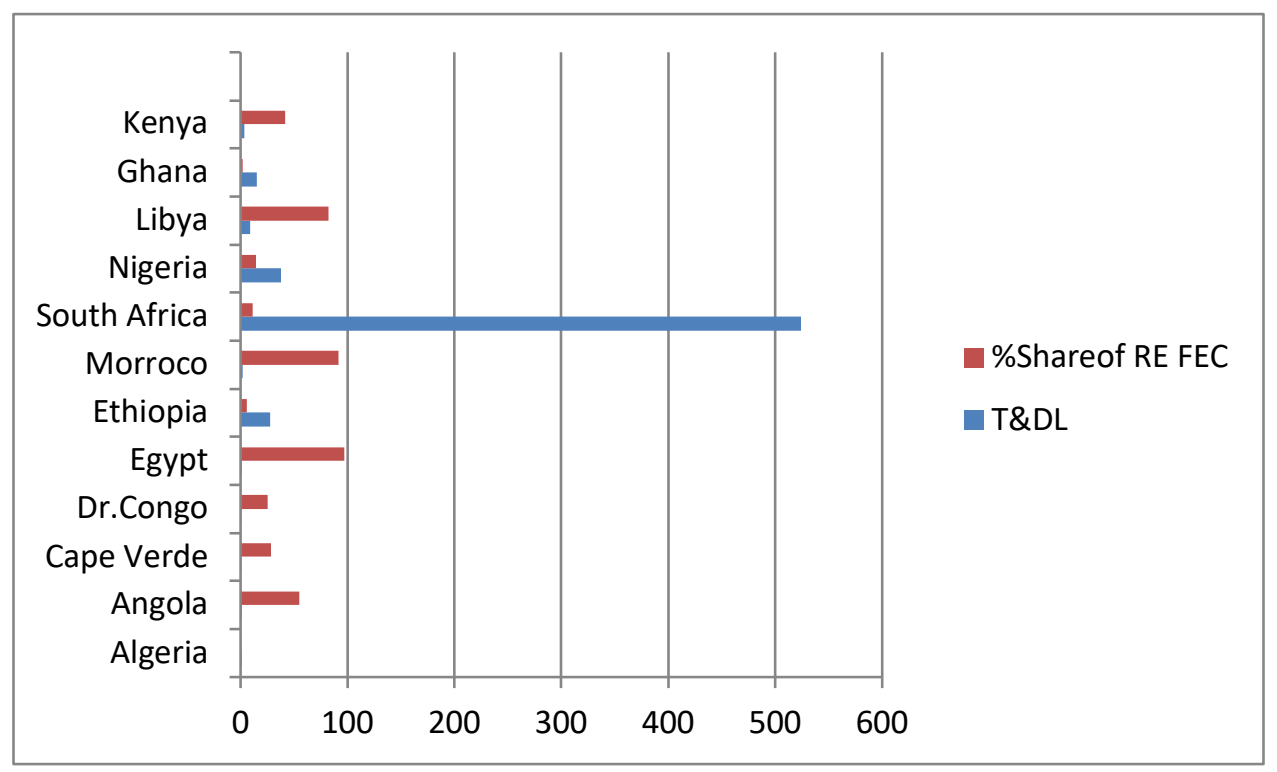

Figure 6 depicts the transmission and distribution losses and shares of renewables in the study countries' grid systems. As was expected, South Africa came out as having the highest transmission and distribution losses. The results show a strong indication that the countries with the highest transmission and distribution losses generate less energy from renewable sources. Thus, there is an inverse relationship between renewables power generation and transmission and distribution losses. Kenya generates over $60 \%$ of its power from geothermal, Wind, and Solar, and tend to have small to nonexistent transmission losses. Same as DR. Congo, Angola, Cape Verde, whose cumulative renewables consumption is very high. The intuition behind this result is that renewables provide space for Distributed generation (DG) or behind the meter generation (BTM). Thus, the more customers generate under DG; the less the TD\&L would come on the system, other than the allowable technical losses.

Expectedly, Ghana equally has significant distribution, and transmission losses as Ghana consumes less than $0.01 \%$ of renewables in its cumulative power generation(Sun et al., 2020). According to(Gyamfi et al., 2018), Ghana has had about 27\% TD\&L for the past four decades since 2003 due to inefficiencies in revenue mobilization and metering systems. Nigeria, too, has significant transmission and transmission losses, as shown in the diagram. Ghana had transmission and distribution losses of $707.33 \mathrm{GWh}$, a $4.43 \%$ increase of cumulative transmitted generated power of $15,960.36 \mathrm{GWh}$, highlighting a 19.01\% increase of the estimated system transmission losses of 594.30 GWh.(Government, 2019). In Africa, most of these losses are either human-induced or technical problems. People cut High Voltage Direct transmissions line for reasons best known to them, causing power losses. The activity harms utilities' revenues on the continent, as they cannot break-even, affecting their power delivering efficiency. The challenge of planning and cost-recovery of integrating variable renewables (VRE) resources to the grid in developing countries is daunting and expensive. Even though the cost associated with transmitting power is very minimal of the total transmission costs, building new transmission infrastructure to convey VRE to market centers is quite substantial, making them adopt new business models of private transmission-owning concession for renewables projects. In Mexico, for instance, they have adopted an approach to share the cost of transmission between the generator and the utility and revised their wheeling charges(Madrigal and Stoft, 2012). (Power for All, 2019) their analysis found that more than 31 countries reported their transmission and distribution losses in SSA between 2010-2015 experienced TD\&L above 20\%, based on their yearly electricity generation. This explains that the countries have TD\&L less than 
$10 \%$, which is the permissible range. That is financially unsustainable and places power utilities in a financial distress situation. There is a need to reform the power in SSA to move away from the vertically integrated traditional model to make them competitive and economically viable.

\section{Conclusion and Policy Implication}

This paper aims to study energy efficiency for 13 African countries for the period 2000-2016. The study's direction was using macroeconomic variables and their past and current trends, together with their decomposed effects on primary energy consumption. The latest data for the 13 countries from the Africa energy Commission (AFREC) was used during the analysis. As a result of the fact that decomposition analysis reacts to variations in different periods, comparing various studies is quite challenging. The IDA method best explains the analysis results, as the difference between them is primarily from the mathematical approach.

The study applied the following energy efficiency indicators; energy intensity, the efficiency of the transformation process (Total primary energy supply divided by Final energy supply, TPES/FEC). Energy Efficiency and its effects on total primary energy supply were researched using the incremental Sun-Shaley decomposition approach. This approach gives precise decomposition results, which can be summed up to study long-run horizons without missing information. As a result, this makes the Sun/Shapley decomposition method suitable for analyzing annual changes. (Ang, 1995)(Vehmas et al., 2018)(Colinet et al., 2016).

Drawing an inference from the descriptive statistics, the summary descriptive statistics show the mean variation among the countries is very high for transmission and distribution losses, GDPs of the countries, TPES, and Final energy consumption. In contrast, carbon intensity (CI) and per capita emissions have low mean variations. The figure is in sharp contrast to the more developed countries on the continent, where per capita emission and carbon intensity are very high. The countries tend to have higher transmission and distribution losses. The analysis indicates the slow improvement in energy efficiency programs in most countries, as shown in the energy efficiency indicators. The analysis aptly describes the energy situation in the study population and the continent as a whole.

Africa's BP scenarios showed that the power sector would be the primary energy user, followed by industry, and transport will continue to consume the bulk of the final energy from now to 2040. Besides, oil will continue to be the dominant fuel until 2040 but will reduce to $34 \%$ from $44 \%$ today. Gas will increase considerably, while renewables will overtake coal as the second preferred choice for generating electricity on the continent due to falling costs. Coal will nearly be phased out, while Nuclear still exists, and hydro a power generator of choice.

From the decomposition analysis, all the energy efficiency indicators have positive values. The population is on a higher pedestal, confirming most projections from notable institutions like the IMF, the world Bank, AfDB, and several others. The per capita income of the countries studied has been on a steady growth path.

Energy intensity (FEC/GDP), as well as the efficiency of the transformation of primary energy (TPES/FEC) into final Consumption, has been growing among the countries. The low percentage of changes shows the less diversified nature of the primary energy supply on the continent. The countries 
are experiencing a lock-in state regarding diversifying their energy mix from fossil fuels and increasing renewables consumption. Additionally, the countries also experience transmission and distribution losses; it is even more pronounced for SSA countries on the study, except Morocco, with the highest transmission losses. It was clear from the survey that countries with significant proportions of renewables in their power generation mix also tend to have lower transmission and distribution losses.

African countries need to structurally change their economies and sectoral energy intensities and institute mandatory energy efficiency policies to be practiced and embrace emerging energy generating technologies such as wind and solar to change this unsustainable trajectory. African countries can benchmark from global best practices regarding policy design, implementation while adapting to country-specific circumstances that will enrich their energy efficiency policy portfolio. (IEA, 2020).

In addressing the energy efficiency challenges, policies need to be implemented. Most of the policies are directed at individual households' decision-making regarding the adoption of Energy efficient adoption technologies. Such as tax reduction, Subsidies, discounts, prohibitions, and promoting awareness campaigns include some of the policies aimed at influencing the adoption decisions of households. There are also regulatory rules like performance standards, building codes, trade restrictions that determine the availability of choices households make regarding the adoption of technologies. However, there are relatively new policy instruments like energy efficiency tenders, tradable white certificates, and energy efficiency obligations that are not directed at households but other parties in the energy efficiency chain. The use of clunker -for- cash approach, as a means to push for the adoption of electric vehicles (EVs) by individuals, especially in the developing world, where people patronize second vehicles, which pollute the environment, is a measure that needs to be implemented fully by African countries. In the case of Africa, the unemployed could be given cash in returning energy inefficient appliances to be recycled. These can also help to curb the dumping of energy-inefficient appliances. 


\section{References}

Agency, I. E. (2019) 'Energy Efficiency 2019', p. 110. Available at:

https://webstore.iea.org/download/direct/2891.

Alemzero, D. A. et al. (2020) 'Assessing energy security in Africa based on multi-dimensional approach of principal composite analysis'.Available at:

https://link.springer.com/article/10.1007/s11356-020-10880-3. Accessed $29^{\text {th }}$ March 2021

Agyarko, K. A., Opoku, R. and Van Buskirk, R. (2020) 'Removing barriers and promoting demand-side energy efficiency in households in Sub-Saharan Africa: A case study in Ghana', Energy Policy. Elsevier Ltd, 137(November), p. 111149. doi: 10.1016/j.enpol.2019.111149.

Ang, B. W. (1995) 'Decomposition methodology in industrial energy demand analysis', energy, 20(11), pp. 1081-1095. doi: 10.1016/0360-5442(95)00068-R.

Ang, B. W. (2004) 'Decomposition analysis for policymaking in energy: Which is the preferred method?', Energy Policy, 32(9), pp. 1131-1139. doi: 10.1016/S0301-4215(03)00076-4.

Ang, B. W. (2006) 'Monitoring changes in economy-wide energy efficiency: From energy-GDP ratio to composite efficiency index', Energy Policy, 34(5), pp. 574-582. doi:

10.1016/j.enpol.2005.11.011.

AFREC (2016) 'African energy efficiency program project at-a-glance' Available at.

https://afrecenergy.org/publications/u4eafrec/U4E_FACTSHenergy efficiencyTS_AFRICA\%20ENERGY\%20EFFICIENCY\%20PROGRAM.pdf

Bank African Development (2019) African Economic Outlook 2019: Macroeconomic performance and prospects Jobs, growth, and firm dynamism Integration; Integration for Africa's economic prosperity. Available at:

https://www.afdb.org/fileadmin/uploads/afdb/Documents/Publications/2019AEO/AEO_2019EN.pdf.

Cansino, J. M., Sánchez-Braza, A. and Rodríguez-Arévalo, M. L. (2015) ‘Driving forces of Spain’s CO2 emissions: A LMDI decomposition approach', Renewable and Sustainable Energy Reviews. Elsevier, 48, pp. 749-759. doi: 10.1016/j.rser.2015.04.011.

Castellano, A. et al. (2015) 'Powering Africa',Available at: https://www.mckinsey.com/industries/oil-and-gas/our-insights/global-energy-perspective2019

Chang, Y.-F. and Huang, B.-N. (2020) 'Factors Leading to Increased Carbon Dioxide Emissions of the APEC Countries: The LMDI Decomposition Analysis', The Singapore Economic Review. doi: 10.1142/s0217590820500125.

Clack, C. T. M. et al. (2019) 'The coal cost crossover : economic viability of existing coal compared to new local wind and solar resources. Available at: https://energyinnovation.org/wpcontent/uploads/2019/03/Coal-Cost-Crossover_Energy-Innovation_VCE_FINAL.pdf

Colinet Carmona, M. J. and Román Collado, R. (2016) 'LMDI decomposition analysis of energy consumption in Andalusia (Spain) during 2003-2012: the energy efficiency policy implications', Energy Efficiency, 9(3), pp. 807-823. doi: 10.1007/s12053-015-9402-y. 
Connecting the Dots. Why only 2\% of global renewable in Africa? (2020) ' Avaialble at: www.res4africa.org/libr (April), pp. 79-91

IEA (2019) 'IEA 2019 IEA 2019'.Available at: https://www.iea.org/reports/africa-energy-outlook2019

Gmbh, R. B. and Phone, G. (2004) 'Assessment of Global Mitigation Progress : A Decomposition of CO 2 Emissions for the world's Top Emitting Countries', pp. 1-20.

Gyamfi, S. et al. (2018) 'The energy efficiency situation in Ghana', Renewable and Sustainable Energy Reviews, 82(June 2017), pp. 1415-1423. doi: 10.1016/j.rser.2017.05.007.

IEA (2020) 'Global Commission for Urgent Action on Energy Efficiency Recommendations of the Global', (June). Available at: https://iea.blob.core.windows.net/assets/d40d5638-1f45-42acb072-fe9e6417cc1e/Global-Commission-Recommendations.pdf.

IEA (2020), SDG7: Data and Projections, IEA, Paris https://www.iea.org/reports/sdg7-data-andprojections

Inglesi-Lotz, R. (2018) 'decomposing the South African CO2 emissions within a BRICS countries context: Signaling potential energy rebound effects', energy. Elsevier BV, 147, pp. 648-654. doi: 10.1016/j.energy.2017.12.150.

Inglesi-Lotz, R. and Blignaut, J. N. (2011) 'South Africa’s electricity consumption: A sectoral decomposition analysis’, Applied Energy. Elsevier Ltd, 88(12), pp. 4779-4784. doi: 10.1016/j.apenergy.2011.06.018.

International Renewable Energy Agency (IRENA) (2020) 'the Energy Progress Report 2020'. Available at: https://trackingsdg7.esmap.org/data/files/downloaddocuments/tracking_sdg_7_2020-full_report_-_web_0.pdf.

Kaltenegger, O. (2020) 'What drives total real unit energy costs globally? A novel LMDI decomposition approach', Applied Energy. Elsevier, 261(July 2019), p. 114340. doi: 10.1016/j.apenergy.2019.114340.

Kazimierczuk, A. H. (2019) 'Wind energy in Kenya : A status and policy framework review', Renewable and Sustainable Energy Reviews. Elsevier Ltd, 107(March), pp. 434-445. doi: 10.1016/j.rser.2018.12.061.

Kim, S. (2017) 'LMDI decomposition analysis of energy consumption in the Korean manufacturing sector’, Sustainability (Switzerland), 9(2). doi: 10.3390/su9020202.

McKinsey \& Company (2019) 'Global Energy Perspective 2019 : Reference Case', Energy Insights, (January), p. 31.

Mokveld, K. and Eije, S. von (2018) 'Final Energy report Kenya', pp. 1-37.Available at: https://www.rvo.nl/sites/default/files/2019/01/Final-Energy-report-Kenya.pdf

Moutinho, V. et al. (2018) 'Factors affecting CO2 emissions in top countries on renewable energies: A LMDI decomposition application', Renewable and Sustainable Energy Reviews, 90(January 2017), pp. 605-622. doi: 10.1016/j.rser.2018.02.009.

Mathew, S. (2007) Wind energy: Fundamentals, resource analysis and economics, Wind Energy: Fundamentals, Resource Analysis and Economics. doi: 10.1007/3-540-30906-3.

'GWEC (2019).Africa Wind Energy Handbook Available at: : https://gwec.net/africa-wind-energyhandbook/ 
Olanrewaju, O. A. (2019) 'Analysing Impacts Responsible for South Africa's Energy Consumption: LMDI Application', Ienergy efficiencyE International Conference on Industrial Engineering and Engineering Management, pp. 1593-1596. doi: 10.1109/Ienergy efficiencyM44572.2019.8978872.

Outlook, B. P. E. (2019) 'BP Energy Outlook - 2019Insights from the Evolving transition scenario Available at: https://www.bp.com/content/dam/bp/businesssites/en/global/corporate/pdfs/energy-economics/energy-outlook/bp-energy-outlook-2019.pdf

Palm, J. and Thollander, P. (2020) Reframing energy efficiency in industry: A discussion of definitions, rationales, and management practices, Energy and Behaviour. Elsevier Inc. doi: 10.1016/b978-0-12-818567-4.00007-7.

Pappis, I., Howells, M., Sridharan, V., Usher, W., Shivakumar, A., Gardumi, F. and Ramos, E. (2019) Energy projections for African countries. doi: 10.2760/678700.

Pillai, N. (2019) ‘Energy Efficiency Indicators : Estimation Methods', (97653).Available at:https://mpra.ub.uni-muenchen.de/97653/

Government of Ghana. (2019) ‘Electricity Supply Plan' Available at:http://energycom.gov.gh/files/2019\%20Electricity\%20Supply\%20Plan.pdf

Scaling up Renewable Power in Africa (2020), p. 55. Available at: https://www.mculture.go.th/mculture th/download/king9/Glossary_about_HM_King_Bhumibol_Adulyadej' s_Funeral.pdf.

SEWEA (2019) 'South Africa's utility-scale wind \& re industry Key data as at March 2019', (March), pp. 1-2.Available at: https://sawea.org.za/wp-content/uploads/2019/03/Stats-andFacts-SAWEA_March-2019.pdf.pp. 1-2.

RISE(2016) ‘Energy efficiency’. Available at: https://rise.esmap.org/data/files/reports/rise 2018 _energy_efficiency.pdf

RISE (2021). Available at: https://rise.worldbank.org/reports (Accessed: 31 January 2021).

Streatfeild, J. E. J. (2018) 'Low Electricity Supply in Sub-Saharan Africa: Causes, Implications, and Remedies', Journal of International Commerce \& Economics, (June), p. 1. Available at: http://www.usitc.gov/journals.

Sun, H. et al. (2020) 'Energy insecurity, pollution mitigation, and renewable energy integration : prospective of wind energy in Ghana'. Environmental Science and Pollution Research.

Trimble, C. (2016) 'Financial Viability of Electricity Sectors in Sub-Saharan Africa Quasi-Fiscal Deficits and Hidden Costs', (August).Available at:

https://documents.worldbank.org/en/publication/documentsreports/documentdetail/182071470748085038/financial-viability-of-electricity-sectors-in-sub-saharan-africaquasi-fiscal-deficits-and-hidden-costs. Accessed $29^{\text {th }} 2021$

'United for efficiency in Tunisia Project at-a-glance' (2016), Available at : https://united4efficiency.org/wp-content/uploads/2019/03/U4E-Tunisia-Factsheet.pdf

US EIA (2018) ‘Country Analysis Brief: Egypt’, Country Analysis Brief: iran, 18, pp. 1-7. Available at:

https://www.eia.gov/beta/international/analysis_includes/countries_long/United_Arab_Emirat es/uae.pdf. 
Vehmas, J., Kaivo-oja, J. and Luukkanen, J. (2018) 'Energy efficiency as a driver of total primary energy supply in the EU-28 countries - incremental decomposition analysis', Heliyon, 4(10). doi: 10.1016/j.heliyon.2018.e00878.

Wall, R. F. (1960) An Atlas of Africa, International Affairs. doi: 10.2307/2610110. 